\title{
Intrapartum risk factors for newborn encephalopathy: the Western Australian case-control study
}

\author{
Nadia Badawi, Jennifer J Kurinczuk, John M Keogh, Louisa M Alessandri, Fiona O’Sullivan, \\ Paul R Burton, Patrick J Pemberton, Fiona J Stanley
}

Editorial

by Edwards

TVW Telethon

Institute for Child

Health Research,

PO Box 855, West

Perth, Western

Australia 6872,

Australia

Nadia Badawi,

neonatologist

Jennifer J

Kurinczuk,

epidemiologist

Louisa M

Alessandri,

senior research officer

Fiona O'Sullivan,

research midwife

Fiona J Stanley,

director

Department of

Obstetrics and

Gynaecology,

Hornsby

Ku-ring-Gai

Hospital, Hornsby,

New South Wales

2077, Australia

John M Keogh,

obstetrician

Department of

Paediatrics,

University of

Western Australia,

Western Australia

6907, Australia

Paul R Burton,

senior biostatistician

Princess Margaret

Hospital for

Children, Subiaco,

Western Australia

6008, Australia

Patrick J

Pemberton,

neonatologist

Dr Alessandri died

in August 1997

Correspondence to:

Dr N Badawi,

Department of

Neonatology, New

Children's Hospital,

Royal Alexandra

Hospital for

Children, PO Box

3515, Parramatta,

New South Wales,

New South Wales

2124, Australia

nadiaB@nch.edu.au

BMJ 1998;317:1554-8

\author{
Abstract \\ Objective To identify intrapartum predictors of \\ newborn encephalopathy in term infants. \\ Design Population based, unmatched case-control \\ study. \\ Setting Metropolitan area of Western Australia, June \\ 1993 to September 1995. \\ Subjects All 164 term infants with moderate or severe \\ newborn encephalopathy; 400 randomly selected \\ controls. \\ Main outcome measures Adjusted odds ratio \\ estimates.
}

Results The birth prevalence of moderate or severe newborn encephalopathy was 3.8/1000 term live births. The neonatal fatality was $9.1 \%$. Maternal pyrexia (odds ratio 3.82), a persistent occipitoposterior position (4.29), and an acute intrapartum event (4.44) were all risk factors for newborn encephalopathy. More case infants than control infants were induced $(41.5 \%$ and $30.5 \%$, respectively) and fewer case infants were delivered by caesarean section without labour $(3.7 \%$ and $14.5 \%$, respectively). Operative vaginal delivery (2.34) and emergency caesarean section (2.17) were both associated with an increased risk. There was an inverse relation between elective caesarean section (0.17) and newborn encephalopathy. After application of a set of consensus criteria for elective caesarean section only three $(7 \%)$ eligible case mothers compared with $33(65 \%)$ eligible control mothers were sectioned electively. Of all the case infants, $113(69 \%)$ had only antepartum risk factors for newborn encephalopathy identified; 39 (24\%) had antepartum and intrapartum factors; eight $(5 \%)$ had only intrapartum factors; and four $(2 \%)$ had no recognised antepartum or intrapartum factors.

Conclusions The causes of newborn encephalopathy are heterogeneous and many relate to the antepartum period. Elective caesarean section has an inverse association with newborn encephalopathy.

Intrapartum hypoxia alone accounts for only a small proportion of newborn encephalopathy. These results question the view that most risk factors for newborn encephalopathy lie in the intrapartum period.

\section{Introduction}

Previous studies of newborn encephalopathy have focused almost exclusively on the intrapartum causes of "hypoxic ischaemic encephalopathy."1-7 The contribution of intrapartum events to newborn encephalopathy remains unclear. We report the intrapartum findings from the Western Australian case-control study of newborn encephalopathy.

\section{Subjects and methods}

The subjects and methods are as reported in the accompanying paper.

\section{Results}

Intrapartum period

Maternal pyrexia, a persistent occipitoposterior position, and an acute intrapartum event were all labour related events associated with a significantly increased risk of newborn encephalopathy (table 1). Only nine of the 18 affected infants and none of the nine control infants whose mothers had experienced pyrexia had a pathogenic organism isolated from mother or baby. A prolonged interval from rupture of membranes to delivery, abnormalities in blood pressure, a nuchal cord, cord prolapse, and shoulder dystocia were associated with a non-significantly increased risk.

\section{Onset of labour and final mode of delivery}

The final mode of delivery is determined by the delivery plan and response to intrapartum events. As the delivery plan could not be determined onset of labour was investigated as a surrogate (table 1). The same proportion of cases and controls had spontaneous onset of labour. More case infants than control infants, however, were induced and fewer case infants were delivered by caesarean sections without labour.

Overall, a similar proportion of case and control infants were delivered by caesarean sections (23\% (38) and 24\% (96), respectively). Relative to spontaneous vaginal delivery, instrumental vaginal delivery and emergency section were associated with over a twofold increased risk of encephalopathy. Only 2.4\% (four) affected infants compared with $14.5 \%$ (58) of control infants were delivered by elective section, defined as one planned at least 24 hours before the procedure (adjusted odds ratio relative to spontaneous vaginal delivery $0.17 ; 95 \%$ confidence interval 0.05 to 0.56 ). This inverse relation was not explained by social factors, including health insurance status, as these had been adjusted for. The documented indications for elective sections among case and control infants are shown in table 2; previous caesarean section was the most common.

To ascertain whether different risk factor profiles explained the differences in proportion of emergency and elective caesarean sections, 14 practising consultant obstetricians from Perth were asked to develop a set of criteria which would lead them to recommend an elective section at term in the interest of the baby. The consensus, which was developed without knowledge of the study results, comprised intrauterine growth restriction, malpresentation, abnormal antepartum cardiotocography, two previous sections, macrosomia with diabetes or gestational diabetes, active herpes, and a previous difficult labour. When we applied these consensus criteria to mothers of case and control infants (table 3) eligible mothers of case infants were 24 times less likely (unadjusted odds ratio relative to spontaneous vaginal delivery $24.2 ; 6.61$ to 90.1 ) than eligible 
mothers of control infants to have been sectioned electively. Nearly $40 \%$ of the eligible case infants were eventually delivered by an emergency section and nearly $20 \%$ were delivered instrumentally or by vaginal breech delivery. The consensus criteria met by eligible mothers are summarised in table 4 . This shows that even in the group that met the consensus criteria there was a difference in antepartum risk factor profiles between cases and controls.

\section{Other intrapartum factors}

The presence of an abnormal intrapartum cardiotocogram, meconium stained liquor, and fetal distress are usually considered to reflect intrapartum hypoxia and were not included in the adjusted analyses as they were likely to be along a causal pathway for, or the first signs of, newborn encephalopathy or were markers of encephalopathy. Inclusion of these variables in the adjusted analysis would have masked the effects of other variables that were working through them. Half the affected infants had intrapartum cardiotocography performed compared with $30 \%$ of control infants. The cardiotocogram was described as abnormal in $61 \%$ of affected infants compared with $37 \%$ of control infants (unadjusted odds ratio $4.43 ; 1.81$ to 10.85 ). Meconium was described more commonly in case infants than control infants $(33 \%$ v 12\%; 3.72; 2.33 to 5.95) and grade III meconium in particular was much more common in case infants $(13 \% v 1.0 \% ; 16.7 ; 5.76$ to 50.0). Finally, fetal distress during labour was recorded by the midwife more often in case infants than control infants $(21 \% v 8 \% ; 3.16 ; 1.84$ to 5.43$)$. For the same reason we did not include immediate characteristics of the newborn (table 5) in the adjusted analysis.

\section{Contribution of possible intrapartum hypoxia}

In an attempt to estimate the proportion of infants who had been exposed to possible intrapartum hypoxia we used the following modified criteria: presence of an abnormal intrapartum cardiotocogram or abnormal fetal heart rate on auscultation or fresh meconium in labour, or both, together with a 1 minute Apgar score of less than 3 and a 5 minute Apgar score of less than $7 .^{9}$ Cord $\mathrm{pH}$ measurements were not included because they were performed so infrequently. Thirty one affected infants (19\%) and two control infants $(0.5 \%)$ fulfilled these criteria. A further 16 cases did not strictly fulfil the definition, but there was evidence that they had experienced a significant intrapartum event which may have been associated with intrapartum hypoxia (for example, breech presentation, birth before arrival at hospital, head stuck, Apgar scores not measured). Therefore, a total of 47 case infants $(29 \%)$ had evidence of having experienced intrapartum hypoxia. Only seven of these (4\% of all cases), however, fulfilled the criteria of possible intrapartum hypoxia in the absence of preconceptional or antepartum abnormalities. Four case infants $(2 \%)$ had no recognised antepartum risk factors or evidence of intrapartum hypoxia and $113(69 \%)$ had only antepartum factors identified (figure 1). Only 15 of these 47 case infants met the consensus eligibility criteria for an elective caesarean section.
Table 1 Risk factors for newborn encephalopathy present in intrapartum period and adjusted for factors before birth and antepartum

\begin{tabular}{|c|c|c|c|c|}
\hline Risk factor & $\begin{array}{c}\text { No }(\%) \text { of } \\
\text { cases }(n=164)\end{array}$ & $\begin{array}{c}\text { No }(\%) \text { of } \\
\text { controls }(n=400)\end{array}$ & $\begin{array}{l}\text { Unadjusted } \\
\text { odds ratio }\end{array}$ & $\begin{array}{l}\text { Adjusted odds ratio* } \\
\qquad(95 \% \mathrm{CI})\end{array}$ \\
\hline \multicolumn{5}{|l|}{ Occipitoposterior presentation: } \\
\hline No & $147(89.6)$ & 385 (96.2) & $1 \dagger$ & $1 \dagger$ \\
\hline Yes & $17(10.4)$ & $15(3.8)$ & 2.97 & $4.29(1.74$ to 10.54$)$ \\
\hline \multicolumn{5}{|l|}{ Maternal pyrexia $\left(\geqslant 37.5^{\circ} \mathrm{C}\right)$ : } \\
\hline No & $146(89.0)$ & $391(97.8)$ & $1 \dagger$ & $1 \dagger$ \\
\hline Yes & $18(11.0)$ & $9(2.2)$ & 5.34 & $3.82(1.44$ to 10.12$)$ \\
\hline \multicolumn{5}{|l|}{ Acute intrapartum eventł: } \\
\hline No & $151(92.1)$ & $395(98.8)$ & $1 \dagger$ & $1 \dagger$ \\
\hline Yes & $13(7.9)$ & $5(1.2)$ & 6.80 & $4.44(1.30$ to 15.22$)$ \\
\hline \multicolumn{5}{|c|}{ Membrane rupture to delivery interval $>12$ hours: } \\
\hline No & $132(80.5)$ & $347(86.7)$ & $1 \dagger$ & $1 \dagger$ \\
\hline Yes & $32(19.5)$ & $53(13.2)$ & 1.59 & 1.31 (0.69 to 2.47$)$ \\
\hline \multicolumn{5}{|l|}{ Blood pressure abnormalities: } \\
\hline No & $154(93.9)$ & $383(95.8)$ & $1 \dagger$ & $1 \dagger$ \\
\hline Yes & $10(6.1)$ & $17(4.2)$ & 1.46 & 1.78 (0.61 to 5.15$)$ \\
\hline \multicolumn{5}{|l|}{ Nuchal cord: } \\
\hline No & $142(86.6)$ & $369(92.2)$ & $1 \dagger$ & $1 \dagger$ \\
\hline Yes & $22(13.4)$ & $31(7.8)$ & 1.84 & 1.81 (0.85 to 3.86$)$ \\
\hline \multicolumn{5}{|l|}{ Cord prolapse: } \\
\hline No & $163(99.4)$ & $399(99.8)$ & $1 \dagger$ & $1 \dagger$ \\
\hline Yes & $1(0.6)$ & $1(0.2)$ & 2.45 & $4.71(0.21$ to 105.02$)$ \\
\hline \multicolumn{5}{|l|}{ Onset of labour: } \\
\hline Spontaneous & $90(54.9)$ & $220(55.0)$ & $1 \dagger$ & $1 \dagger$ \\
\hline Induced & $68(41.5)$ & $122(30.5)$ & 1.36 & 0.97 (0.57 to 1.68$)$ \\
\hline None & $6 \S(3.7)$ & $58(14.5)$ & 0.25 & $0.17(0.06$ to 0.49$)$ \\
\hline \multicolumn{5}{|l|}{ Mode of delivery: } \\
\hline Spontaneous vaginal & $49(29.9)$ & $261(40.3)$ & $1 \dagger$ & $1 \dagger$ \\
\hline Induced vaginal & $32(19.5)$ & $80(20)$ & 1.31 & 1.10 (0.55 to 2.18$)$ \\
\hline Instrumental vaginal & $42(25.6)$ & $62(15.5)$ & 2.23 & 2.34 (1.16 to 4.70$)$ \\
\hline Elective caesarean section & $4(2.4)$ & $58(14.5)$ & 0.23 & $0.17(0.05$ to 0.56$)$ \\
\hline Emergency caesarean section & $34(20.7)$ & $38(9.5)$ & 2.94 & 2.17 (1.01 to 4.64$)$ \\
\hline Breech manoeuvre & $3(1.8)$ & $1(0.3)$ & 9.86 & $1.54(0.10$ to 25.14$)$ \\
\hline \multicolumn{5}{|l|}{ Shoulder dystocia: } \\
\hline No & $155(94.5)$ & $393(98.3)$ & $1 \dagger$ & $1 \dagger$ \\
\hline Yes & $9(5.5)$ & $7(1.7)$ & 3.26 & $3.0(0.77$ to 11.67$)$ \\
\hline \multicolumn{5}{|l|}{ General anaesthesia: } \\
\hline No & $146(89.0)$ & $389(97.2)$ & $1 \dagger$ & $1 \dagger$ \\
\hline Yes & $18(11.0)$ & $11(2.8)$ & 4.40 & 3.08 (1.16 to 8.17$)$ \\
\hline \multicolumn{5}{|l|}{ Epidural anaesthesia: } \\
\hline No & $145(88.4)$ & $331(82.8)$ & $1 \dagger$ & $1 \dagger$ \\
\hline Yes & $19(11.6)$ & $69(17.2)$ & 0.64 & $0.51(0.26$ to 1.02$)$ \\
\hline
\end{tabular}

*Adjusted for maternal age, parity, employment status, health insurance status, race, family history of epilepsy and other neurological disease, infertility treatment, hypertension, height, thyroid disease, pre-eclampsia, moderate or severe bleeding, viral illness, alcohol consumption, gestational age, centile birth weight, infant sex, appearance of placenta, late or no antenatal care, hospital of delivery, and plurality. †Baseline comparison group. łHaemorrhage $(n=7)$, maternal convulsions $(n=2)$, rupture of uterus $(n=1)$, snapped cord $(n=1)$, and birth of baby before arrival at obstetric facility $(n=2)$. §lncludes two women who had emergency caesarean sections before onset of labour.

Table 2 Indications for elective caesarean section documented by midwife according to whether baby had newborn encephalopathy (cases) or not (controls)

Indication

No delivered by caesarean Controls ( $\mathrm{n}=58$ )

Previous caesarean section 32

Malpresentations

Previous difficult labour

Intrauterine growth retardation

Placenta previa

Other reasons*

Cases $(\mathrm{n}=4)$

Two previous caesarean sections

One previous caesarean section

Intrauterine growth retardation

${ }^{*}$ One each of antepartum fetal tachycardia, active herpes infection, nephrotic syndrome, cephalopelvic disproportion, pre-eclampsia with inflammatory bowel syndrome, oligohydramnios, macrosomia, maternal request, reason not given. 
Table 3 Details of onset of labour and final mode of delivery in cases (babies with newborn encephalopathy) and controls by eligibility for elective caesarean section according to consensus criteria. ${ }^{*}$ Values are numbers (percentages) of subjects

\begin{tabular}{|c|c|c|c|c|}
\hline \multirow[b]{2}{*}{ Detail } & \multicolumn{2}{|c|}{ Cases } & \multicolumn{2}{|c|}{ Controls } \\
\hline & $\begin{array}{l}\text { Elective section } \\
\text { candidates }(n=43)\end{array}$ & $\begin{array}{l}\text { Others } \\
(n=121)\end{array}$ & $\begin{array}{l}\text { Elective section } \\
\text { candidates }(n=51)\end{array}$ & $\begin{array}{l}\text { Others } \\
(\mathrm{n}=349)\end{array}$ \\
\hline \multicolumn{5}{|l|}{ Labour onset: } \\
\hline Spontaneous & $19(44.2)$ & $71(58.7)$ & $9(17.7)$ & $211(60.5)$ \\
\hline Induced & $20(46.5)$ & $48(39.7)$ & $9(17.7)$ & $113(32.4)$ \\
\hline None & $4 †(9.3)$ & $2(1.7)$ & $33(64.7)$ & $25(7.2)$ \\
\hline \multicolumn{5}{|l|}{ Final mode of delivery: } \\
\hline Elective caesarean & $3(7.0)$ & $1(0.8)$ & $33(64.7)$ & $25(7.2)$ \\
\hline Non-elective caesarean & $17(39.5)$ & $17(14.1)$ & $7(13.7)$ & $31(8.9)$ \\
\hline Instrumental and breech & $8(18.6)$ & $37(30.6)$ & $4(7.8)$ & $59(16.9)$ \\
\hline Induced vaginal & $8(18.6)$ & $24(19.8)$ & $5(9.8)$ & 75 (21.5) \\
\hline Spontaneous vaginal & 7 (16.3) & $42(34.7)$ & $2(3.9)$ & $159(45.6)$ \\
\hline
\end{tabular}

*Eligiblity defined by consensus opinion of 14 obstetricians. Consensus list was intrauterine growth retardation, malpresentation, abnormal antepartum cardiotocogram, two previous caesarean sections, macrosomia with diabetes or gestational diabetes, active herpes, and previous difficult labour.

†Includes two women who had emergency caesarean sections before onset of labour.

Table 4 Consensus criteria met by mothers of cases (babies with newborn encephalopathy) and controls eligible for elective caesarean section. * Values are numbers (percentages) of subjects

\begin{tabular}{lcc} 
Consensus criteria* $^{*}$ & $\begin{array}{c}\text { Eligible cases } \\
(\mathbf{n = 4 3 )}\end{array}$ & $\begin{array}{c}\text { Eligible controls } \\
(\mathbf{n}=\mathbf{5 1})\end{array}$ \\
\hline Predicted infant weight $<3$ rd centile & $21(48.8)$ & $5(9.8)$ \\
\hline Abnormal antepartum cardiotocogram & $14(32.6)$ & $8(15.7)$ \\
\hline Breech and other malpresentations & $9(20.9)$ & $21(41.2)$ \\
\hline Two previous caesareans & $3(7.0)$ & $12(23.5)$ \\
\hline Previous difficult labour & $0(0)$ & $4(7.8)$ \\
\hline Gestational diabetes and macrosomia & $1(2.3)$ & $0(0)$ \\
\hline Active herpes & $0(0)$ & $2(3.9)$ \\
\hline
\end{tabular}

${ }^{*}$ These criteria are not mutually exclusive.

\section{Discussion}

Our results indicate that intrapartum hypoxia alone accounts for only a small proportion of cases of newborn encephalopathy, and elective caesarean section had an unexpected inverse association with newborn encephalopathy.

\section{Role of intrapartum hypoxia}

Although 29\% of affected infants experienced events traditionally indicative of birth asphyxia, it does not necessarily follow that asphyxia was the primary cause of the encephalopathy. While some intrapartum factors may be single causes-that is, a previously normal baby who becomes encephalopathic in labour (fig 2 , pathway 1)-this was an uncommon scenario in our study (see fig 1). Other factors may be on a causal pathway that starts before birth but which includes intrapartum hypoxia as a contributor (figure 2, pathway 2). For example, growth restriction alone is associated with newborn encephalopathy ${ }^{8}$ and exposure to labour may compound that damage. ${ }^{10} \mathrm{~A}$ further possibility is that the intrapartum factors are merely markers of damage associated with adverse events before birth (fig 2, pathway 3). Abnormality on a cardiotocogram, meconium stained liquor, low Apgar scores, or the need for active resuscitation may simply reflect previous neurological compromise. ${ }^{11}$

A very small proportion of infants had no recognised antepartum risk factors nor evidence of intrapartum hypoxia, and it remains unclear as to when their encephalopathy started and what caused it.
Over two thirds of affected infants had only antepartum factors identified. Together these two groups represent over $70 \%$ of cases among which there was no evidence of adverse intrapartum events. This points to the antepartum period being of prime aetiological importance in most cases of newborn encephalopathy.

\section{Infection}

Maternal pyrexia in labour was a significant risk factor, confirming our previous finding. ${ }^{12}$ Prolonged interval between rupture of membranes and delivery, a risk factor for ascending infection, was more common in cases compared with controls but not significantly so. Chorioamnionitis is of current interest as a cause of cerebral palsy in both term ${ }^{13}$ and preterm ${ }^{14}$ infants. The mechanisms of fetal damage, however, are not known but could include cerebral sepsis, hyperthermia, or action via inflammatory mediators. ${ }^{15}$

\section{Caesarean section}

The most striking finding relates to mode of delivery. These data suggest an important inverse association between elective caesarean section and newborn encephalopathy. There are several possible explanations for this finding. Chance alone is an unlikely explanation, as shown by the $95 \%$ confidence interval, although mode of delivery was not one of the initial study hypotheses. ${ }^{12}$ The results are also unlikely to be due to biased selection of control subjects. The control

Table 5 Immediate characteristics of babies with encepalopathy (cases) and controls. Values are numbers (percentages) of subjects

\begin{tabular}{|c|c|c|}
\hline Characteristic & Cases $(n=164)$ & Controls $(n=400)$ \\
\hline \multicolumn{3}{|l|}{ Apgar at 1 minute: } \\
\hline$<3$ & $50(30.5)$ & $3(0.7)$ \\
\hline $3-6$ & $46(28.1)$ & $37(9.2)$ \\
\hline$>6$ & $67(40.8)$ & $359(89.7)$ \\
\hline Missing & $1(0.6)$ & $1(0.2)$ \\
\hline \multicolumn{3}{|l|}{ Apgar at 5 minutes: } \\
\hline$<3$ & $14(8.5)$ & 0 \\
\hline $3-6$ & $40(24.4)$ & $5(1.2)$ \\
\hline$>6$ & $108(65.9)$ & $394(98.5)$ \\
\hline Missing & $2(1.2)$ & $1(0.2)$ \\
\hline \multicolumn{3}{|l|}{ Onset of respiration: } \\
\hline$\leqslant 2$ minutes & $83(50.6)$ & $373(93.2)$ \\
\hline$>2$ minutes & $68(41.5)$ & $15(3.7)$ \\
\hline Not established & $6(3.7)$ & 0 \\
\hline Missing & $7(4.2)$ & $12(3.0)$ \\
\hline \multicolumn{3}{|l|}{ Airway resuscitation: } \\
\hline None & $30(18.3)$ & $283(58.2)$ \\
\hline Suction alone & $15(9.1)$ & $82(20.5)$ \\
\hline Oxygen & $29(17.7)$ & 49 (12.2) \\
\hline Bag and mask & $35(21.3)$ & $30(7.5)$ \\
\hline Intubation & $44(26.8)$ & $4(1.0)$ \\
\hline Intubation and $\mathrm{CPR}^{*}$ & $10(6.2)$ & 0 \\
\hline Missing & $1(0.6)$ & $2(0.5)$ \\
\hline \multicolumn{3}{|l|}{ Cord pH: } \\
\hline Not measured & $135(82.4)$ & $391(97.7)$ \\
\hline$<7.0$ & $5(3.0)$ & 0 \\
\hline $7.0-7.1$ & $14(8.5)$ & $2(0.5)$ \\
\hline$\geqslant 7.2$ & $9(5.5)$ & $6(1.5)$ \\
\hline Missing & $1(0.6)$ & $1(0.2)$ \\
\hline \multicolumn{3}{|l|}{ Birth trauma: } \\
\hline Present & $17(10.4)$ & 0 \\
\hline
\end{tabular}

${ }^{*}$ Cardiopulmonary resuscitation. 


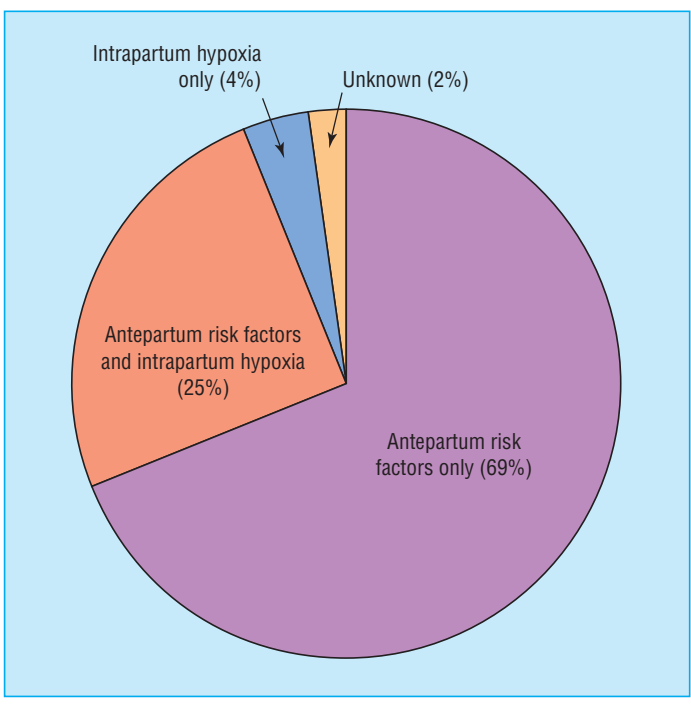

Fig 1 Distribution of risk factors for newborn encephalopathy

$\begin{array}{lll}\text { Antepartum period } & \text { Intrapartum period } & \text { Newborn outcome } \\ 1 & - & \end{array}$

Fig 2 Theoretical scenarios for timing of neurological insult in newborn encephalopathy

subjects were randomly selected and their final mode of delivery and all 21 other characteristics of pregnancy, labour, and infant available for comparison were the same as for all term live births in Western Australia during the study period. ${ }^{16}$ There was no evidence of case selection bias as all affected infants were included and none died before transfer. ${ }^{8}$ We therefore conclude that our findings are real.

A vital distinction, not made in most other studies, is the differentiation between elective and non-elective sections. ${ }^{2} 121718$ Had we failed to make this distinction we would have concluded that caesarean section had no effect on the risk of newborn encephalopathy. When we applied the eligibility criteria for elective sections we found that eligible case infants were more than 20 times less likely to be delivered by elective section than eligible control infants. The reasons for the apparent differences in the management of labour in the cases and controls are undoubtedly complex and may reflect genuine differences (see table 4). Unrecognised high risk features, alternatives to the consensus view, women's choice of vaginal delivery, or perhaps some undefined factors which led a pregnancy to result in a baby with encephalopathy may also have operated to affect the management of delivery. As the definition of an elective caesarean section was one in which there were 24 hours between the decision and delivery, it is also possible that some of these women had been booked for an elective section which they did not receive because they went into labour. On close review of the eligible cases, however, a maximum of only $20 \%$ could possibly fall into this category.

It is of note that even in those women not meeting the consensus criteria for elective section, mothers of control infants were electively sectioned much more commonly than mothers of case infants. Furthermore, eligible mothers of case infants did not avoid operative and instrumental delivery but had emergency rather than elective procedures. Non-elective sections involve inherently more operative and postoperative risk, reflected in the lower maternal morbidity after elective sections. ${ }^{19}$ In addition, the baby delivered by a non-elective section has usually been exposed to the stresses of labour, and this may have an independent impact on outcome.

Elective caesarean sections may exert their apparent beneficial effects by avoiding some of the intrapartum risk factors for encephalopathy. For example, elective sections prevent exposure to post-maturity, persistent occipitoposterior position, intrapartum maternal pyrexia, and catastrophic events in labour. It may be the avoidance of these factors other than caesarean section per se which contributes to its apparent benefit.

We readily recognise that there is no "correct rate" of elective caesarean sections, but it is pertinent to ask whether women who would benefit most are being identified and given access to this method of delivery. It is not possible to say from this observational study whether elective section would have actually changed the outcome in any of the cases, but it is an obvious question and one worthy of further investigation. As a trial to answer this question is unlikely ever to be performed, ${ }^{20}$ however, observational studies such as this would probably be our only source of information. It is, however, pertinent to note that our findings cannot be used to argue on a very wide basis that disability can be prevented by elective caesarean section.

Increasingly, the debate about the aetiology of perinatal brain injury emphasises the relatively small contribution of the intrapartum period. The presence of antepartum events does not mean that the intrapartum course did not contribute to the final outcome. Nevertheless, even with the best care not all potentially damaging intrapartum events are avoidable. It seems likely, however, that many babies already have encephalopathy before labour and others, whose reserve is diminished at the onset of labour, may have less capacity to cope with hypoxia when it occurs

\section{Key messages}

- Intrapartum risk factors for newborn encephalopathy include maternal pyrexia, persistent occipitoposterior position, and acute intrapartum events

- Operative vaginal delivery and emergency caesarean section were both associated with an increased risk whereas there was an inverse relation with elective caesarean section

- There was no evidence of intrapartum hypoxia in over $70 \%$ of cases of newborn encephalopathy

- The causes of newborn encephalopathy are heterogeneous and many relate to the antepartum period

- These findings bring into question the view that most risk factors for newborn encephalopathy lie in the intrapartum period 
during labour. Elucidating these multiple pathways will be the only way we can go forward in the prevention of newborn encephalopathy.

For acknowledgements and details of contributors, funding, and competing interests please see the accompanying paper.

1 Nelson KB, Leviton A. How much of neonatal encephalopathy is due to birth asphyxia? Am J Dis Child 1991;145:1325-31

2 Finer NN, Robertson CM, Richards RT, Pinnell LE, Peters KL. Hypoxicischemic encephalopathy in term neonates: perinatal factors and outcome. J Pediatr 1981;98:112-7.

3 Ergander U, Eriksson M, Zetterstrom R. Severe neonatal asphyxia. Incidence and prediction of outcome in the Stockholm area. Acta Paediatr 1983;72:321-5.

4 Levene ML, Kornberg J, Williams THC. The incidence and severity of post-asphyxial encephalopathy in full-term infants. Early Hum Develop $1985 ; 11: 21-6$.

5 Hull J, Dodd KL. Falling incidence of hypoxic-ischaemic encephalopathy in term infants. Br J Obstet Gynaecol 1992;99:386-91.

6 Thornberg E, Thiringer K, Odeback A, Milsom I. Birth asphyxia: incidence, clinical course and outcome in a Swedish population. Acta Paediatr 1995;84:927-32

7 Sarnat HB, Sarnat MS. Neonatal encephalopathy following fetal distress. Arch Neurol 1976;33:696-705.

8 Badawi N, Kurinczuk JJ, Keogh JM, Alessandri LM, O'Sullivan F, Burton PR, et al. Antepartum risk factors for newborn encephalopathy: the Western Australian case-control study. BMJ 1998;317:1549-53.

9 Committee on Fetus and Newborn, American Academy of Paediatrics, and Committee on Obstetric Practice, American College of Obstetricians and Gynecologists. Use and abuse of the Apgar score. Pediatrics 1996;98:141-2.
10 Berg AT. Indices of fetal growth retardation, perinatal hypoxia-related factors and childhood neurological morbidity. Early Hum Dev 1989;19:271-83.

11 Spencer JAD, Badawi N, Burton PR, Keogh JM, Pemberton PJ, Stanley FJ The intrapartum CTG prior to neonatal encephalopathy at term: a case control study. Br J Obstet Gynaecol 1997;104:25-8.

12 Adamson SJ, Alessandri LM, Badawi N, Burton PR, Pemberton PJ, Stanley FJ. Predictors of neonatal encephalopathy in full term infants. BMJ 1995;311:598-602

13 Grether JK, Nelson KB. Maternal infection and cerebral palsy in infants of normal birth weight. JAMA 1997;278:207-11

14 Murphy DJ, Hope PL, Johnson A. Neonatal risk factors for cerebral palsy in very preterm babies: case-control study. BMJ 1997;314:404-8.

15 Leviton A. Preterm birth and cerebral palsy: is tumour necrosis factor the missing link? Dev Med Child Neurol 1993;35:553-8.

16 Gee V. Perinatal statistics in Western Australia: 12th Annual Report of the Western Australian Midwives Notification System for 1994. Perth: Health Department of Western Australia, 1995.

17 Ziegler AL, Calame A, Marchand C, Passera M, Reymond-Goni I, Prod'Hom LS. Cerebral distress in full-term newborns and its prognostic value. A follow-up study of 90 infants. Helvetica Paediatrica Acta 1976;31:299-317.

18 De Souza SW, Richards B. Neurological sequelae in newborn babies after perinatal asphyxia. Arch Dis Child 1978;53:564-9.

19 van Ham MAPC, van Dongen PWJ, Mulder J. Maternal consequences of caesarean section. A retrospective study of intra-operative and post-operative maternal complications of caesarean section during a 10 year period. Eur J Obstet Gynecol Reprod Biol 1997;74:1-6.

20 Lumley J, Lester A, Renou P, Wood C. A failed RCT to determine the best method of delivery for very low birth weight infants. Cont Clin Trials $1985 ; 6: 120-7$

(Accepted 27 August 1998)

\title{
Subdural haemorrhages in infants: population based study
}

\author{
S Jayawant, A Rawlinson, F Gibbon, J Price, J Schulte, P Sharples, J R Sibert, A M Kemp
}

Editorial by Lloyd
Department of
Child Health,
University of Wales
College of
Medicine, Academic
Centre, Llandough
Hospital, Penarth,
Vale of Glamorgan
CF64 2XX
A M Kemp,
senior lecturer
J R Sibert,
professor
S Jayawant,
senior registrar
A Rawlinson,
consultant
paediatrician
F Gibbon,
consultant in
paediatric neurology
Department of
Child Health,
Southmead
Hospital, Bristol
BS10 5NB
J Price,
consultant
paediatrician
continued over

continued over

BMJ 1998;317:1558-6

\begin{abstract}
Objectives To identify the incidence, clinical outcome, and associated factors of subdural haemorrhage in children under 2 years of age, and to determine how such cases were investigated and how many were due to child abuse.

Design Population based case series.

Setting South Wales and south west England.

Subjects Children under 2 years of age who had a subdural haemorrhage. We excluded neonates who developed subdural haemorrhage during their stay on a neonatal unit and infants who developed a subdural haemorrhage after infection or neurosurgical intervention.
\end{abstract}

Main outcome measures Incidence and clinical outcome of subdural haemorrhage in infants, the number of cases caused by child abuse, the investigations such children received, and associated risk factors.

Results Thirty three children (23 boys and 10 girls) were identified with subdural haemorrhage. The incidence was 12.8/100 000 children/year (95\% confidence interval 5.4 to 20.2). Twenty eight cases $(85 \%)$ were under 1 year of age. The incidence of subdural haemorrhage in children under 1 year of age was 21.0/100 000 children/year and was therefore higher than in the older children. The clinical outcome was poor: nine infants died and 15 had profound disability. Only 22 infants had the basic investigations of a full blood count, coagulation screen, computed tomography or magnetic resonance imaging, skeletal survey or bone scan, and ophthalmological examination. In retrospect, 27 cases $(82 \%)$ were highly suggestive of abuse.

Conclusion Subdural haemorrhage is common in infancy and carries a poor prognosis; three quarters of such infants die or have profound disability. Most cases are due to child abuse, but in a few the cause is unknown. Some children with subdural haemorrhage do not undergo appropriate investigations. We believe the clinical investigation of such children should include a full multidisciplinary social assessment, an ophthalmic examination, a skeletal survey supplemented with a bone scan or a skeletal survey repeated at around 10 days, a coagulation screen, and computed tomography or magentic resonance imaging. Previous physical abuse in an infant is a significant risk factor for subdural haemorrhage and must be taken seriously by child protection agencies.

\section{Introduction}

Subdural haemorrhage in infants and young children presents major challenges in diagnosis to doctors, social workers, and courts. It has been recognised as a form of severe child abuse as far back as 1860, but little is known about the epidemiology or prognosis of the condition. ${ }^{1-4}$ In clinical practice, it is often difficult to deduce whether a subdural haematoma in an infant is caused by accident or abuse. ${ }^{5}$ The shaken baby syndrome is well described both clinically and pathologically, but there are few epidemiological accounts of this condition that is associated with death and disability. ${ }^{6}$

We performed a population based case series study of children under the age of 2 years who had a 